\title{
Reductions of Intergranular Corrosion Resistance and Wear Resistance in a Ni-Cr-Mo-Based Superalloy by Aging-Treatment-Induced Precipitation
}

\author{
Pengyan Zhang ${ }^{1,2}$, Chi Zhang ${ }^{3, *}$, Xiaoguang Zhou ${ }^{4}$ and Zhenyi Huang ${ }^{1,2}$ \\ 1 Key Laboratory of Metallurgical Emission Reduction \& Resources Recycling, Anhui University of Technology, \\ Ministry of Education, Maanshan 243032, China; zpy5102@163.com (P.Z.); huangzhenyi@ahut.edu.cn (Z.H.) \\ 2 School of Metallurgical Engineering, Anhui University of Technology, Maanshan 243032, China \\ 3 School of Materials Science and Engineering, Dalian University of Technology, Dalian 116024, China \\ 4 State Key Laboratory of Rolling Technology and Automation, Northeastern University, \\ Shenyang 116024, China; zhouxg@ral.neu.edu.cn \\ * Correspondence: zhangchi@dlut.edu.cn; Tel.: +86-0411-8470-6087
}

check for updates

Citation: Zhang, P.; Zhang, C.; Zhou, X.; Huang, Z. Reductions of Intergranular Corrosion Resistance and Wear Resistance in a Ni-Cr-Mo-Based Superalloy by Aging-Treatment-Induced Precipitation. Metals 2021, 11, 1329. https://doi.org/10.3390/met11081329

Academic Editor: Belén Díaz Fernández

Received: 6 July 2021

Accepted: 17 August 2021

Published: 23 August 2021

Publisher's Note: MDPI stays neutral with regard to jurisdictional claims in published maps and institutional affiliations.

Copyright: (c) 2021 by the authors. Licensee MDPI, Basel, Switzerland. This article is an open access article distributed under the terms and conditions of the Creative Commons Attribution (CC BY) license (https:// creativecommons.org/licenses/by/ $4.0 /)$.

\begin{abstract}
Ni-Cr-Mo-based superalloy is widely used as a key component in many critical environments. To ensure that the manufacturing process does not impact the long-term service performance of these components, the aging precipitation behavior at different temperatures and its effect on intergranular corrosion (IGC) resistance and wear resistance of a Ni-Cr-Mo-based C276 superalloy were investigated. The equilibrium phase diagram was calculated first using thermodynamic software to confirm the potential phases. Carbides of $\mathrm{M}_{6} \mathrm{C}$ were found to be formed at grain boundaries after aging at $800-850{ }^{\circ} \mathrm{C}$ for short-term treatment. The other two phases ( $\mu$ phase and $\mathrm{P}$ phase) indicated in the phase diagram were not observed for the samples after aging treatment up to $15 \mathrm{~h}$. Furthermore, double loop electrochemical potentiokinetic reactivation (DL-EPR) tests were conducted to examine the IGC resistance. The degree of sensitization increased with the aging time and severe corrosion was found to occur at grain boundaries. For the first time, the influence of aging treatment on the wear behavior of this superalloy has been specifically studied. Concerning the hot processing of $\mathrm{Ni}$-Cr-Mo-based C276 superalloy, these results indicate the importance of avoiding high-temperature heat treatment for long periods.
\end{abstract}

Keywords: Ni-Cr-Mo-based superalloy; aging treatment; precipitation; intergranular corrosion resistance; wear resistance

\section{Introduction}

Superalloys usually preserve excellent high-temperature performance, resulting in them being widely used in many industries with intense conditions, such as aerospace, chemical, nuclear, etc. C276 superalloy is one of the most promising superalloys belonging to the Ni-Cr-Mo-based family, with good corrosion resistance, high temperature strength, and creep resistance [1-4]. This superalloy was first developed by dramatically reducing the content of carbon and optimizing the alloying elements [5]. The outstanding advantage of this superalloy is that it can be used directly in a welding state without severe intergranular corrosion (IGC) attack [6,7].

Due to the excellent properties of C276 superalloy, it is an ideal candidate material of some key components in the nuclear industry [8-10]. The material was designed to be used in temperatures below $650{ }^{\circ} \mathrm{C}$. However, during the manufacture process, $\mathrm{C} 276$ superalloy needs to undergo heat treatments at elevated temperatures for a certain period of time in some cases. Recently, a new technology, named hot vacuum bulging technology, was developed to manufacture a rotor can, which is a key component in nuclear reactor coolant pumps, using C276 superalloy [11,12]. The hot vacuum bulging processing is conducted at $800{ }^{\circ} \mathrm{C}$ for $2 \mathrm{~h}$ to realize exact forming through creep deformation. Creep age 
forming (CAF) is an effective forming technology for aluminum alloys, and potentially has applications with superalloys [13]. Therefore, the effect of high-temperature aging on performance during the manufacture process (which is much higher than the service temperature) becomes a main concern for $\mathrm{C} 276$ superalloy.

C276 superalloy is used in solution state with single austenite phase. There is no need to apply aging treatment to this superalloy to optimize the precipitation of $\gamma^{\prime}$ and/or $\gamma^{\prime \prime}$, such as the precipitation-strengthened superalloys [14,15]. Previous investigations into the aging treatment of C276 superalloy focused mainly on testing the stability of performance during long-term service. Liu et al. found that massive block $\mu$ phase and $\mathrm{M}_{6} \mathrm{C}$ carbides precipitated in the $\mathrm{C} 276$ superalloy after aging at $700{ }^{\circ} \mathrm{C}$ for more than $360 \mathrm{~h}$, and the precipitates grew along with the aging time [16]. The tensile test at $700{ }^{\circ} \mathrm{C}$ indicated that the aged samples maintained the tensile strength with a small decrease in plasticity until $2160 \mathrm{~h}$. The fracture of the tested sample still presented ductile morphology. Akhter et al. tested the effect of aging treatment on the hardness and impact energy of C276 superalloy [17]. The authors found that Mo-rich $\mu$ phase precipitated after aging at $850^{\circ} \mathrm{C}$ for $48 \mathrm{~h}$, associated with a dramatic decrease in impact energy. Raghavan et al. have characterized the three distinct second phases, $\mu$ phase, $\mathrm{M}_{6} \mathrm{C}$ carbides, and $\mathrm{P}$ phase, in the long-term aged C276 superalloy using transmission electron microscopy (TEM) [5]. The chemical compositions are remarkably close for the three kinds of precipitates. The authors defined the precipitates using a transmission electron microscope.

However, the influence of short-term aging treatment on the performance of this kind of superalloy has been given little attention. There are indications that short-term aging at high temperature can also induce precipitation in other Ni-Cr-Mo-based superalloys [18,19]. A similar phenomenon was also observed in C276 superalloy when it was aging treated at $800{ }^{\circ} \mathrm{C}$ for a relatively short time [20]. Furthermore, the nuclear reactor coolant pump rotor serves as a protective barrier for the rotor against cyclic erosion of the coolant. The corrosion resistance and wear resistance of $\mathrm{C} 276$ superalloy are key utilized material properties for C276 superalloy. For example, there were clear, synergistic effects between corrosion and wear in this alloy under seawater conditions, leading to corrosion-induced wear and wear-induced-corrosion in tribocorrosion processes [21-23]. According to Hashim and Duraiselvam [24], the tribological properties of C276 superalloy could be improved by laser surface treatment without sacrificing its corrosion properties. Yilbas and Ali also studied the effect of laser treatment on C276 alloy [25]; they found that laser treatment was effective in increasing the surface microhardness and decreasing the friction coefficient. Nevertheless, it is worth noting that no study investigating the effect of aging treatment on the tribological behavior of C276 superalloy has been reported. Our previous paper [20] revealed that small amounts of precipitation resulted in the deterioration of corrosion resistance, but the relationship between precipitation, corrosion behavior, and wear resistance of C276 superalloy is yet to be elucidated. Therefore, the precipitation behavior at different aging treatment temperatures and its influence on the corrosion and wear resistances are highly deserving of an investigation.

The present study is an extension from our previous report [20]. In this work, the equilibrium phase diagram for C276 superalloy was calculated first. Then, based on the thermal dynamic calculation results, aging treatments at two different temperatures were specifically conducted. The aging-treatment-induced precipitations were carefully characterized by SEM and TEM. Moreover, the corrosion resistance, mechanical property, and wear behavior of aging-treated C276 superalloy was evaluated by double-loop electrochemical potentiokinetic reaction (DL-EPR) test, microhardness measurement and ball-on-plate sliding wear test, respectively.

\section{Materials and Methods}

The tested C276 superalloy is a $0.5 \mathrm{~mm}$ thick commercial sheet, which is in solution state with equiaxed austenite grain structure. The chemical composition of the material is: $0.004 \mathrm{C}, 0.01 \mathrm{Si}, 16.00 \mathrm{Cr}, 16.34 \mathrm{Mo}, 5.98 \mathrm{Fe}, 3.46 \mathrm{~W}, 0.25 \mathrm{Co}, 0.04 \mathrm{Cu}, 0.16 \mathrm{~V}, 0.4 \mathrm{Mn}$ 
and balance Ni in wt.\%. More details are available in Ref. [20]. Based on the chemical compositions, thermodynamic software Thermal-Calc (Thermo-Calc Software, Canonsburg, RA, USA) was used to calculate the equilibrium phase diagram. In order to make a comparison with the previous paper [20], the sheets were aging treated in a vacuum furnace at $800{ }^{\circ} \mathrm{C}$ and $850^{\circ} \mathrm{C}$ for $1-15 \mathrm{~h}$, followed by water quenching.

The samples used for microstructure analysis were cut from these aging-treated sheets. After mechanical polishing, the samples were light etched in aquaregia ( $\left.\mathrm{HCl}: \mathrm{HNO}_{3}=3: 1\right)$ for 1-3 min and then examined with a field emission scanning electron microscope (Zeiss Supra 55, Zeiss, Germany). For TEM observation, disks $3 \mathrm{~mm}$ in diameter and $50 \mu \mathrm{m}$ in thickness were electrochemically polished at $-30{ }^{\circ} \mathrm{C}$ in a $5 \%$ perchloric acid ethanol solution and examined in JEM-2100F (Jeol Ltd., Japan, JEM-2100F).

The DL-EPR test was performed to investigate the corrosion resistance of the aged samples. Square samples measuring $15 \times 15 \mathrm{~mm}$ were cut and the sample surfaces were mechanically polished. The conventional solution $\left(0.01 \mathrm{~mol} / \mathrm{L} \mathrm{KSCN}\right.$ and $\left.0.5 \mathrm{~mol} / \mathrm{L} \mathrm{H}_{2} \mathrm{SO}_{4}\right)$ was found to not be applicable for distinguishing the current peaks in the electrochemical tests. In this work, we introduced a new solution of $6 \mathrm{~mol} / \mathrm{L} \mathrm{HCl}$ to investigate the IGC resistance of $\mathrm{C} 276$ superalloy. A saturated calomel electrode (SCE) is served as the reference electrode. The scan started from the potential of $-0.3 \mathrm{~V}_{\mathrm{SCE}}$ to $0.7 \mathrm{~V}_{\mathrm{SCE}}$ with a rate of $1 \mathrm{mV} / \mathrm{s}$, then reversed.

The microhardness was examined using the MHV-2.0 Vickers (Shenzhen Shunhua Instrument Equipment Co., Ltd., Shenzhen, China) hardness tester with a load of $0.25 \mathrm{~N}$. The influence of aging treatment on the wear resistance of C276 superalloy was studied in an acceleration condition using a ball-on-plate wear testing rig. The detailed information about the wear testing rig can be found in the study by Li et al. [26]. Prior to the wear tests, C276 superalloy plates were ground and polished to a final surface roughness of less than $100 \mathrm{~nm}$ [27]. $\mathrm{Al}_{2} \mathrm{O}_{3}$ balls with a diameter of $7 \mathrm{~mm}$ were selected as the counter-body. Wear tests were performed at room temperature and repeated at least three times for each material. The applied normal load on the ball was $10 \mathrm{~N}$ and the sliding speed was $0.92 \mathrm{~m} / \mathrm{min}$. The length of the wear stroke was $12 \mathrm{~mm}$ and the total reciprocating wear test duration was $30 \mathrm{~min}$. During each test, the friction coefficient was automatically calculated and recorded. The worn surface profile was then examined by an optical 3D surface profiler (Super View W1 type, which is manufactured by Shenzhen Zhongtu Instrument Co., Ltd., Shenzhen, China).

\section{Results and Discussion}

\subsection{Thermodynamic Calculation Results}

The equilibrium phase diagram based on the chemical compositions was calculated using thermodynamic software Thermal-Calc. The molar fractions (NP) of phase constituents varying with the temperature is shown in Figure 1. It infers that the $\mu$ phase, $\mathrm{P}$ phase, and $\mathrm{M}_{6} \mathrm{C}$ are supposed to precipitate from the matrix at high temperatures; $\mu$ phase can precipitate at temperatures lower than $772{ }^{\circ} \mathrm{C}, \mathrm{P}$ phase can precipitate in the temperature range of $598-1098^{\circ} \mathrm{C}, \mathrm{M}_{6} \mathrm{C}$ can form at temperatures lower than $1111^{\circ} \mathrm{C}$, and the content increases with the decreasing temperature. The maximum content for the precipitation of $\mathrm{M}_{6} \mathrm{C}$ is $0.14 \mathrm{~mol} \%$. The equilibrium chemical compositions of the precipitations are listed in Table 1 . The precipitations are mainly composed of $\mathrm{Cr}, \mathrm{Mo}, \mathrm{W}$, and $\mathrm{Ni}$. 

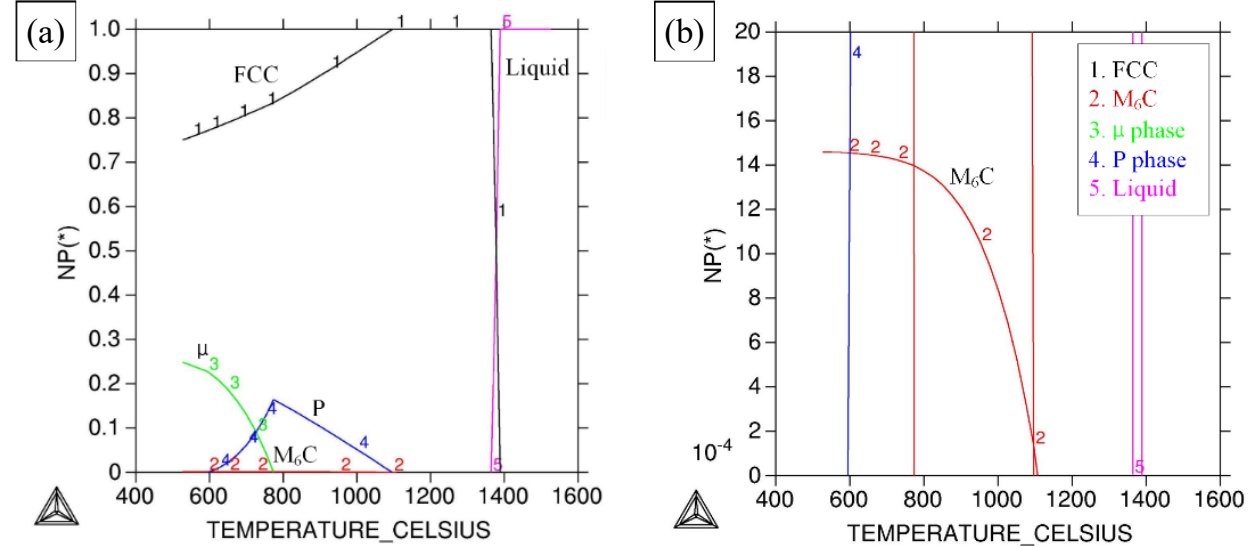

Figure 1. Equilibrium phase diagram (mol\%) predicted by Thermo-Calc software for the tested C276 superalloy. ${ }^{*}$ NP means the molar fraction. (a) The whole phase diagram; (b) magnification of (a).

Table 1. The equilibrium chemical composition of the precipitates (wt.\%).

\begin{tabular}{cccccccc}
\hline & C & Cr & Mo & Fe & W & Co & Ni \\
\hline $\mathrm{P}$ & 0 & 16.00 & 41.87 & 1.05 & 11.5 & 0.01 & 29.45 \\
$\mu$ & 0 & 16.00 & 47.32 & 1.94 & 5.58 & 0.01 & 29.04 \\
$\mathrm{M}_{6} \mathrm{C}$ & 2.48 & 9.17 & 57.9 & 2.60 & 5.38 & 0.007 & 22.40 \\
\hline
\end{tabular}

It should be noted that the equilibrium phase diagram is calculated based on the thermodynamic analysis. It needs time for the diffusion of alloy atoms to form the precipitates. Three kinds of precipitates have been reported to be formed in Ni-Cr-Mo-based superalloy [5,28]. However, the aging treatments were conducted at $650-900{ }^{\circ} \mathrm{C}$ for $1000 \mathrm{~h}$ in the investigation of Raghavan et al. [5]. Akhter et al. heated the samples up to $240 \mathrm{~h}$ to study the effects of aging treatment on the hardness and impact property [17]. They also mentioned that $\mu$ phase cannot form during the aging treatment at $650{ }^{\circ} \mathrm{C}$ within $500 \mathrm{~h}$, while $\mathrm{M}_{6} \mathrm{C}$ may be produced after $10 \mathrm{~h}$ of aging.

\subsection{Precipitate Observations}

In our previous paper [20], the precipitation behavior of C276 superalloy during aging at $800^{\circ} \mathrm{C}$ was studied. In order to understand the influence of aging temperature, the precipitation behavior of $\mathrm{C} 276$ superalloy during aging at $850{ }^{\circ} \mathrm{C}$ was studied and compared with the results of aging at $800^{\circ} \mathrm{C}$. Figure 2 shows the backscattered electron (BSE) images of the aging-treated samples with different aging temperatures. One can determine that some second phases precipitated along the austenite grain boundaries. By comparison, the number of precipitates increases with the increase in aging time and aging temperature. Furthermore, the morphologies of the precipitates seem very similar for all the samples. The amounts of precipitates were observed to be very low for the samples aged within $4 \mathrm{~h}$. Energy dispersive spectrometer (EDS) analysis was used to detect the compositions of the precipitates, as shown in Figure 3. It can be seen that the precipitates are rich in Mo and W as compared to the base material. The compositions are similar to the thermodynamic calculation results as listed in Table 1 . However, it is hard to distinguish the precipitates based on the chemical compositions. 

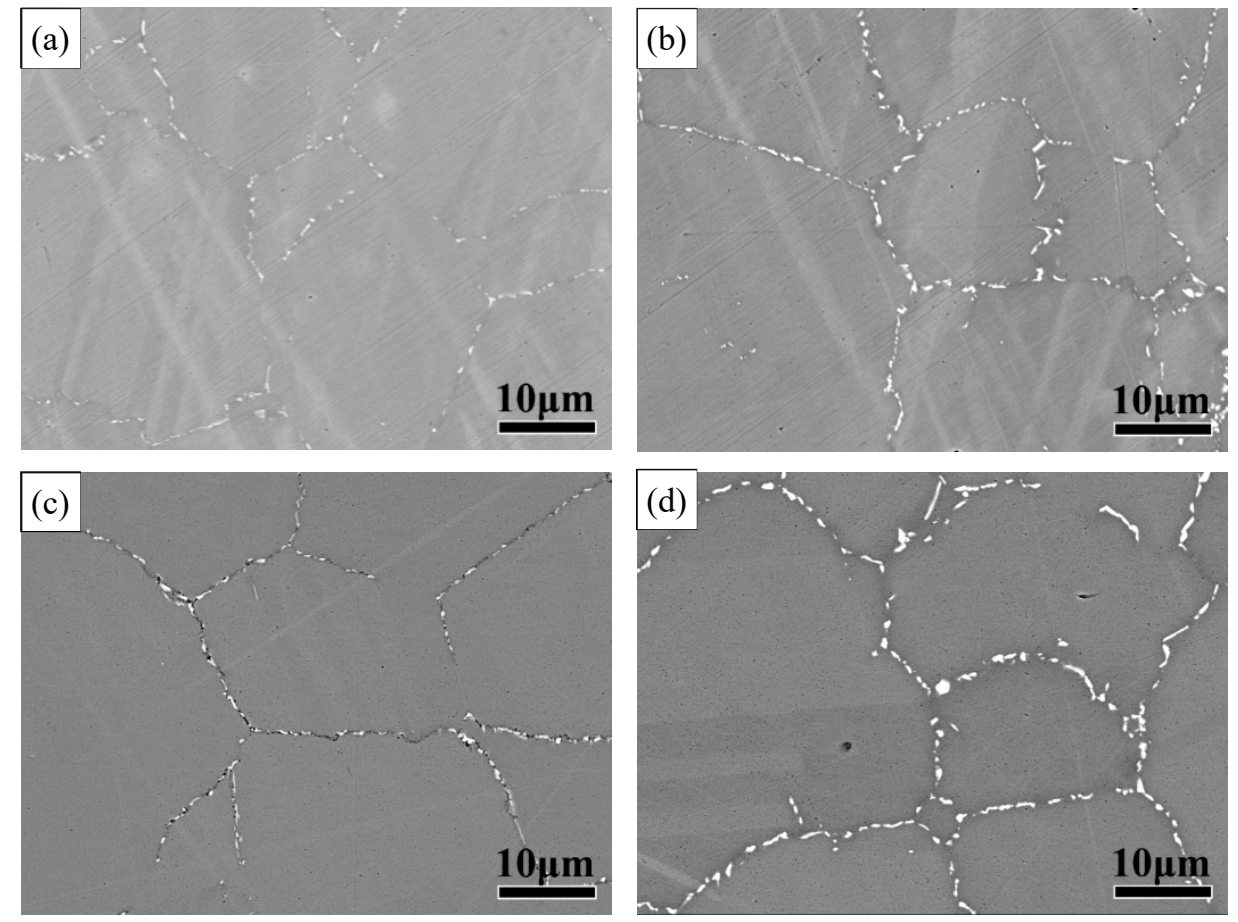

Figure 2. Backscattered electron images of the $\mathrm{C} 276$ superalloy after aging treatments: (a) $800{ }^{\circ} \mathrm{C}$ for $4 \mathrm{~h}$; (b) $800{ }^{\circ} \mathrm{C}$ for $15 \mathrm{~h}$; (c) $850{ }^{\circ} \mathrm{C}$ for $4 \mathrm{~h}$; (d) $850{ }^{\circ} \mathrm{C}$ for $15 \mathrm{~h}$.
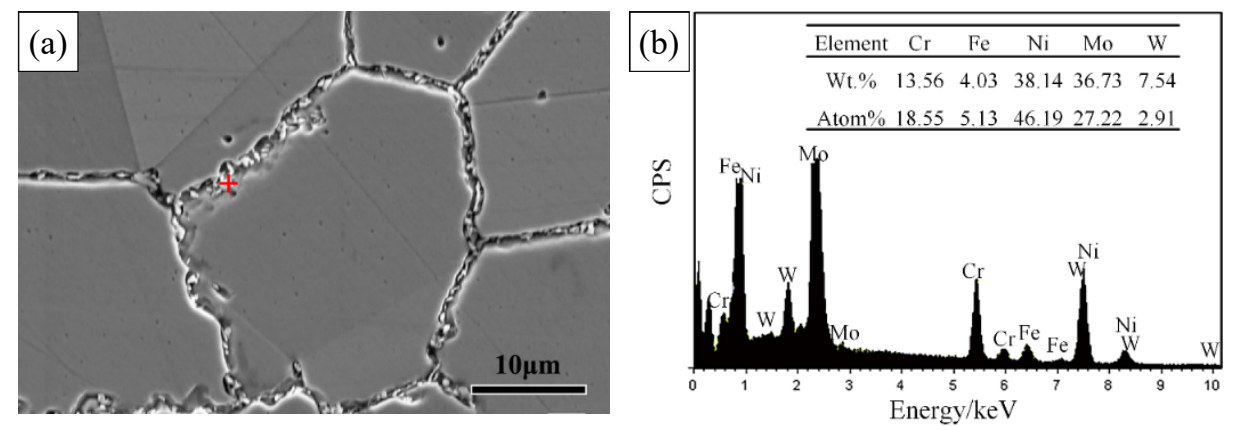

Figure 3. Secondary electron image (a) and EDS analysis (b) of the $\mathrm{C} 276$ superalloy aged at $850{ }^{\circ} \mathrm{C}$ for $15 \mathrm{~h}$.

TEM was used to further confirm the precipitates, as shown in Figure 4. The precipitates were formed at grain boundaries with a twinning boundary. The diffraction pattern indicates that the precipitation is a face-centered cubic (FCC) structure with a lattice constant of $\mathrm{a}=1.11 \mathrm{~nm} . \mathrm{M}_{6} \mathrm{C}$ is reported to have a cubic crystal structure with $\mathrm{a}=1.08-1.12 \mathrm{~nm}[5] . \mu$ phase $\left(\mathrm{A}_{6} \mathrm{~B}_{7}\right.$ type $)$ has a hexagonal close packed structure with $\mathrm{a}=0.476-0.479 \mathrm{~nm}$ and $\mathrm{c}=2.57-2.59 \mathrm{~nm}$, while $\mathrm{P}$ has a tetragonal crystal structure $[5,16]$. Moreover, Raghavan et al. reported that $\mu$ phase and $\mathrm{M}_{6} \mathrm{C}$ were the main precipitates for $\mathrm{C} 276$ superalloy when aging at $650{ }^{\circ} \mathrm{C}-900{ }^{\circ} \mathrm{C}$ up to $1000 \mathrm{~h} \mathrm{[5].} \mathrm{Based} \mathrm{on} \mathrm{the} \mathrm{phase}$ diagram in Figure 1, $\mu$ phase is supposed to precipitate at a temperature below $772{ }^{\circ} \mathrm{C}$. Therefore, the precipitate is supposed to be $\mathrm{M}_{6} \mathrm{C}$, which is consistent with the previous report [20]. No other types of precipitates were observed in TEM analysis. The chemical composition analysis result corresponds to the thermodynamic calculation result in Section 3.1. Therefore, both the thermodynamic calculation and experimental investigation confirm the precipitation of $\mathrm{M}_{6} \mathrm{C}$ carbides in the aging-treated $\mathrm{C} 276$ superalloy. Increasing the aging temperature to $850{ }^{\circ} \mathrm{C}$ does not introduce other precipitates during aging. 

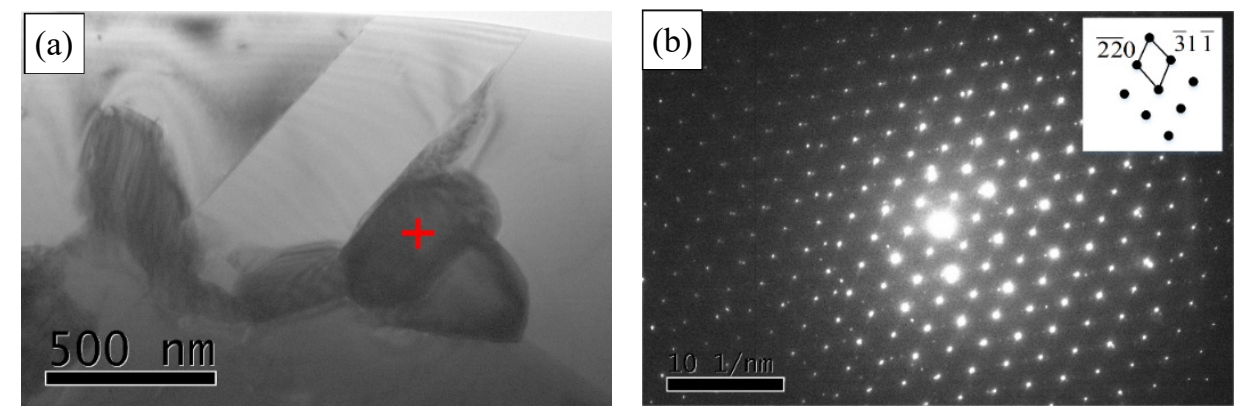

Figure 4. TEM image of precipitates of $\mathrm{M}_{6} \mathrm{C}(\mathbf{a})$ and corresponding diffraction pattern (b) in the sample aged at $850^{\circ} \mathrm{C}$ for $15 \mathrm{~h}$.

\subsection{IGC Behavior}

DL-EPR test was employed to evaluate the degrees of sensitization of the samples aging treated at $850{ }^{\circ} \mathrm{C}$. The representative DL-EPR curves are shown in Figure 5. The current density peaks in the anodic scan loop $\left(I_{a}\right)$ and reverse scan loop $\left(I_{r}\right)$ were determined by the curves. Then, the ratio of $I_{r} / I_{a}$ can be obtained to evaluate the sensitization of IGC. Table 2 lists the determined values for the parameters $I_{a}, I_{r}$, and $I_{r} / I_{a}$. The $I_{a}$ values varied little with the aging time. However, the $I_{r}$ increased along with the aging. Since a new solution was used, the degree of sensitization was used to compare the relative IGC resistance of the samples. It was found that the degree of sensitization of the tested C276 superalloy increases with the aging time. This corresponds to the precipitate observation results, in which the number of precipitates increases with the progression of the aging treatment. Here, a new solution was used to evaluate the IGC behavior of C276 superalloy, which resulted in a large difference between these results and those reported previously [20]. The values in Table 2 indicate that this solution can reflect the degree of sensitization.

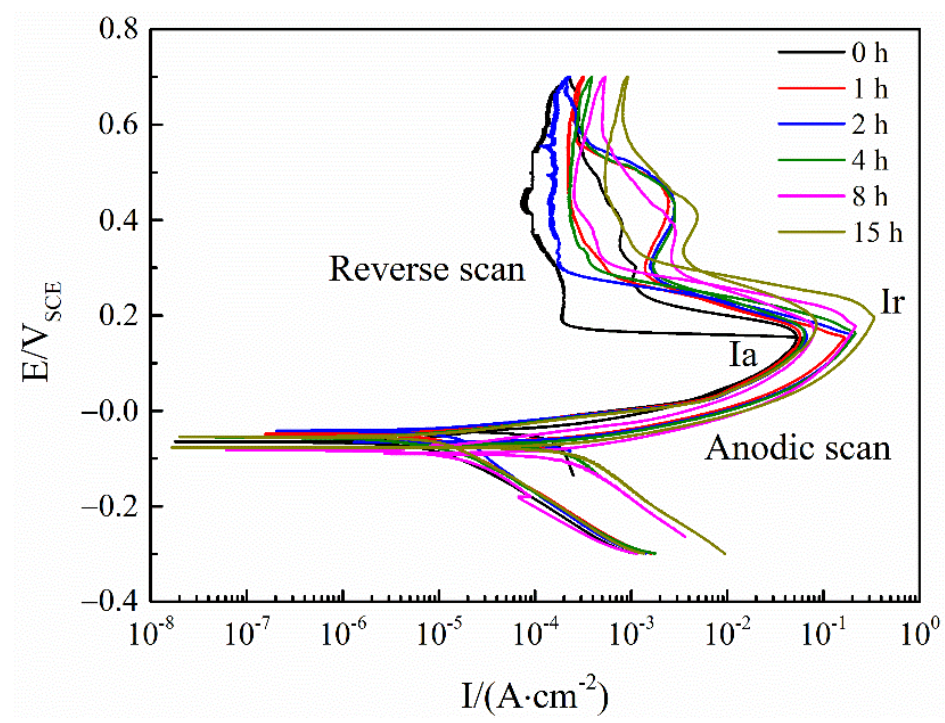

Figure 5. DL-EPR curves of $\mathrm{C} 276$ superalloy after aging treated at $850^{\circ} \mathrm{C}$ for different times.

Table 2. Summary of $I_{a} / I_{r}$, and $I_{r} / I_{a}$ determined based on the DL-EPR tests.

\begin{tabular}{cccc}
\hline Aging Time & $\boldsymbol{I}_{\boldsymbol{a}} \mathbf{( A \cdot \mathbf { c m } ^ { - 2 } )}$ & $\boldsymbol{I}_{\boldsymbol{r}} \mathbf{( \mathbf { A } \cdot \mathbf { c m } ^ { - 2 } )}$ & $\boldsymbol{I}_{\boldsymbol{r}} / \boldsymbol{I}_{\boldsymbol{a}}$ \\
\hline $0 \mathrm{~h}$ & 0.052304 & 0.065186 & 1.246 \\
$1 \mathrm{~h}$ & 0.056988 & 0.16517 & 2.898 \\
$2 \mathrm{~h}$ & 0.066707 & 0.1994 & 2.989 \\
$4 \mathrm{~h}$ & 0.063476 & 0.21418 & 3.374 \\
$8 \mathrm{~h}$ & 0.079404 & 0.27391 & 3.450 \\
$15 \mathrm{~h}$ & 0.084394 & 0.33562 & 3.977 \\
\hline
\end{tabular}


Figure 6 shows the microstructure of samples after DL-EPR tests. The as-received sample shows homogeneous etched morphology after testing. However, for the aged sample, severe corrosion at grain boundaries can be easily defined, as shown in Figure 6b. This indicates that C276 superalloy is sensitive to IGC attack after aging treatment, which agrees well with the DL-EPR curve analysis results.
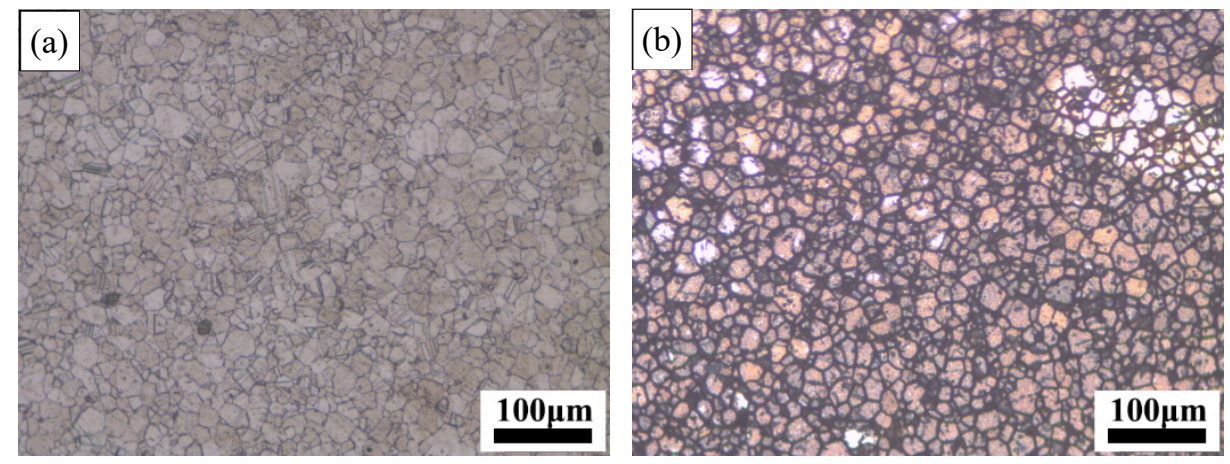

Figure 6. Optical microstructural observation of the samples after DL-EPR tests: (a) as-received material; (b) the sample aged at $800{ }^{\circ} \mathrm{C}$ for $12 \mathrm{~h}$.

The precipitates of $\mathrm{M}_{6} \mathrm{C}$ carbides after aging treatment are rich in Mo and $\mathrm{W}$ as detected by EDS analysis. This results in the formation of Mo- and W-depleted regions adjacent to the grain boundaries [29]. These regions are supposed to be easily attacked by corrosion during etching [30-32]. This implies that the precipitation of carbides during aging at high temperatures for higher than $4 \mathrm{~h}$ is detrimental to the IGC resistance of C276 superalloy. Moreover, the grain boundaries show different corrosion resistances in Figure $6 \mathrm{~b}$. Stratulat and Luo et al. have noticed this phenomenon in stainless steel and aluminum alloy $[33,34]$. They showed that the grain boundaries with high stored energy, which is related to the grain misorientation angle and dislocation density, were easily IGC attacked.

\subsection{Microhardness and Wear Behavior}

The microhardness of $\mathrm{C} 276$ superalloy after aging treatment at $850{ }^{\circ} \mathrm{C}$ was measured with the results displayed in Figure 7. The microhardness is shown to increase from about 330 to $360 \mathrm{HV}$ after aging treatment for $4 \mathrm{~h}$, and then declines very slightly with further increasing the aging time. The aging treatment at $800^{\circ} \mathrm{C}$ led to very similar microhardness in the alloy with the aging treatment at $850^{\circ} \mathrm{C}$. Coupling the analysis with the precipitation observations in Figure 3, the precipitation of $\mathrm{M}_{6} \mathrm{C}$ carbides is supposed to increase the microhardness of the aged C276 superalloy. Such a phenomenon of age hardening has also been found in a C276 alloy coatings by Mulligan and co-authors [35], who interpreted the increase in hardness to the formation of precipitates rich in Mo and Cr. It is worth noting that precipitation mainly occurs at grain boundaries and there is a slight grain growth during aging treatment, as evident from Figure 2; thus, a very small reduction in the microhardness is observed when the alloy is aging treated after $15 \mathrm{~h}$. 


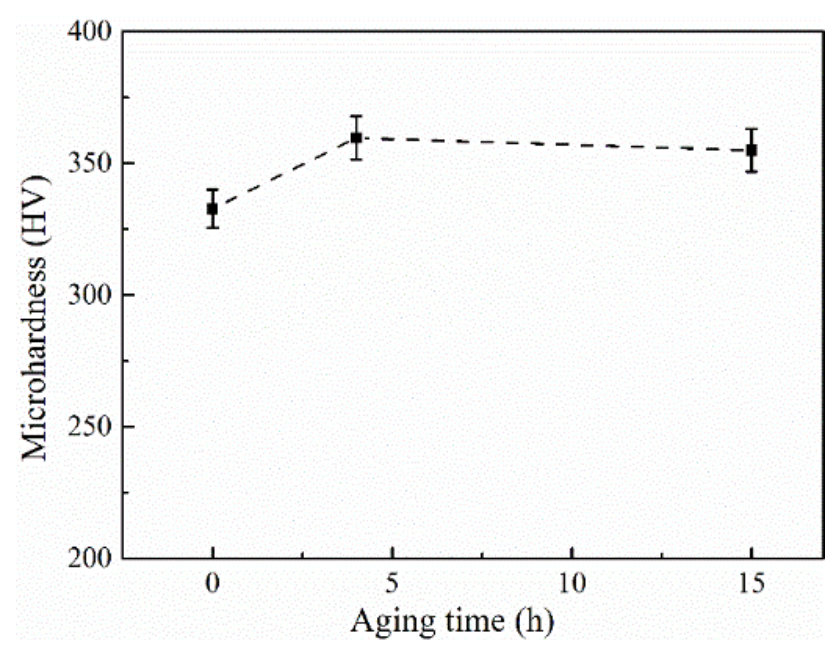

Figure 7. Microhardness of $\mathrm{C} 276$ superalloy after aging treatment at $850{ }^{\circ} \mathrm{C}$ with different aging times.

In previous studies [21-27,36-38], it has been reported that the wear behavior of a metallic material can be affected by many factors, such as its microstructure, phase constitution, mechanical properties, and the sliding wear conditions (including normal load, velocity, and atmosphere). Based on the precipitation results in Figure 2 and microhardness results in Figure 7, the $\mathrm{C} 276$ superalloy samples after aging treatment at $850{ }^{\circ} \mathrm{C}$ for 4 and $15 \mathrm{~h}$ were specifically selected for further wear property evaluations. Figure $8 \mathrm{a}$ shows the typical friction coefficient evolution histories during sliding wear as a function of time. The results reveal that the friction coefficient increases significantly during the early stage of sliding wear and then changes very slightly, indicating a relatively steady-state wear process. Figure $8 \mathbf{b}$ shows the average friction coefficient as a function of microhardness. Of note, the average friction coefficient in this paper is calculated by averaging the results obtained during the steady state wear stage from all three repeated wear tests for each condition. It can be seen from the figure that the average friction coefficient of C276 superalloy without aging treatment is about 0.6. The value is consistent with the typical friction coefficients for dry sliding wear of metallic materials [37]. It is interesting to observe that the friction coefficient increases first after aging treatment for $4 \mathrm{~h}$ and then drops with further increasing the aging time. The friction coefficient evolution tendency is consistent with that of microhardness. As shown in Figure 8b, the average friction coefficient of C276 superalloy increases when its microhardness is increased. The maximum friction coefficient of about 0.95 is achieved in the sample that has the greatest microhardness of about $360 \mathrm{HV}$ corresponding to the aging treatment at $850{ }^{\circ} \mathrm{C}$ for $4 \mathrm{~h}$. These increased friction coefficients in Figure 8 should be attributed to the formation of hard precipitates as displayed in Figure 2. It is obvious that the presence of precipitates not only results in the increase in friction coefficient, but also leads to the fluctuations of friction coefficient during steady state wear process in Figure 8a.
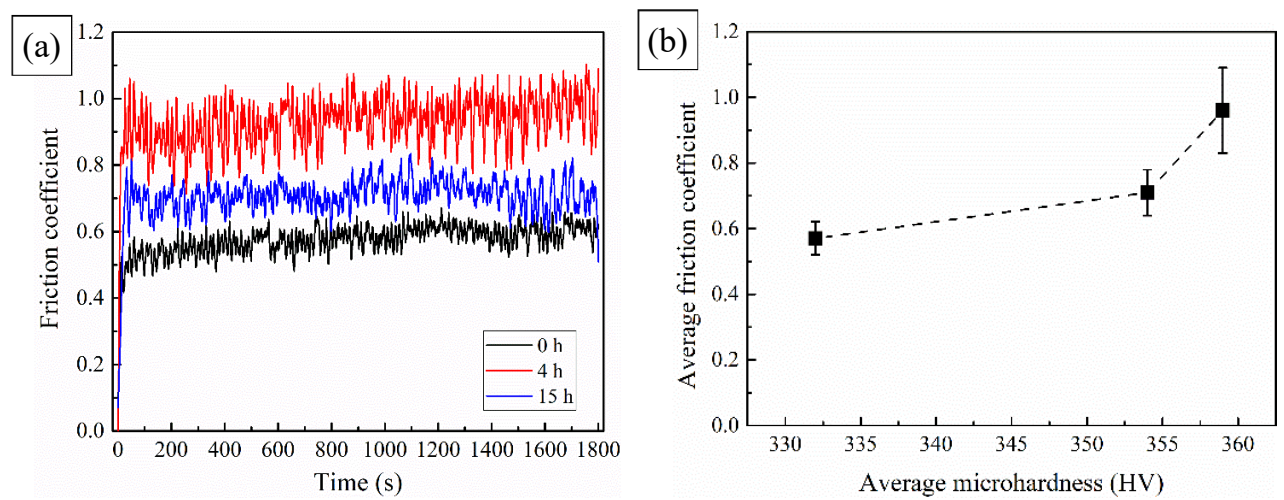

Figure 8. (a) Variations of friction coefficient of the samples during wear test, and (b) the relation between the friction coefficient and microhardness. 
In order to reveal the influence of aging treatment on the wear resistance and wear mechanisms of C276 superalloy, the 3D wear track surface morphologies after wear test are characterized with the results shown in Figure 9. Obvious furrow marks associated with wear debris can be found in all the samples as labelled in the figures, indicating the severe abrasion wear. The samples with and without aging treatment show a great difference in the morphologies of furrow. Narrow and shallow wear marks develop in the C276 superalloy without aging treatment. On the contrary, remarkably wider and deeper grooves are found in the aged treated samples. To further analyze the surface morphologies after wear, the surface profiles were detected and drawn together in Figure 10. The wear track width and depth are about $373 \mu \mathrm{m}$ and $5.5 \mu \mathrm{m}$, respectively, for the as-received alloy while increasing to about $1490-1530 \mu \mathrm{m}$ and $21-22 \mu \mathrm{m}$, respectively, for the aged samples. It is evident that aging treatment of C276 superalloy leads to much larger wear tracks, indicating the obvious reductions of its wear resistance.

Although the microhardness increases after aging treatment, the wear resistance was reduced. Based on the observations on the wear tracks in Figure 9, it is estimated that the $\mathrm{M}_{6} \mathrm{C}$ carbides may fall off from the material and increase the wear volume in the form of a third body during abrasive friction. This effect is different from the fine precipitates in the matrix, in which the fine scale precipitates can improve the wear resistance in the form of precipitation strengthening [38-40]. The increase in microhardness of C276 superalloy after aging treatment is caused by the formation of $\mathrm{M}_{6} \mathrm{C}$ carbides. However, these precipitates mainly formed at grain boundaries, as confirmed in Figures 2-4. The precipitation at grain boundaries could deteriorate the mechanical properties of the matrix. Therefore, to preserve the good wear resistance of the C276 superalloy, the selection of aging treatment temperature and time should be very carefully selected. It is worth noting that this study is the first report considering the influence of aging treatment on the wear behavior of $\mathrm{C} 276$ superalloy, and a more comprehensive investigation on the mechanisms and sliding-wear-induced microstructure changes will be reported in our future research.

(a)

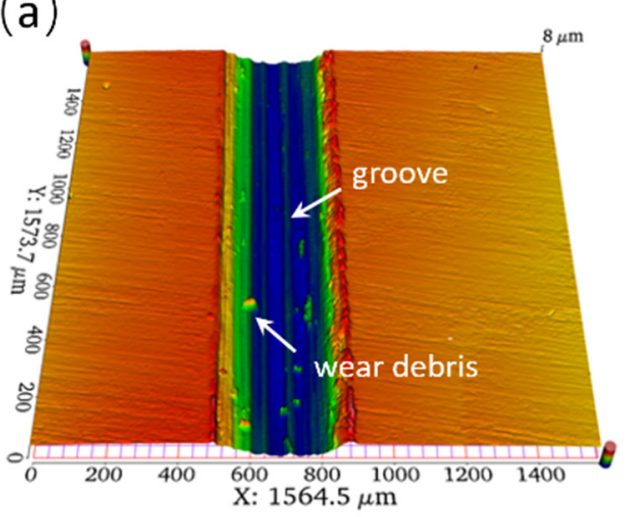

(c)

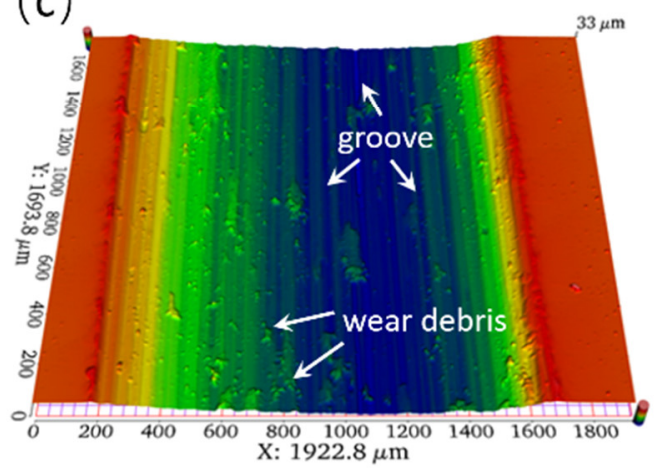

(b)

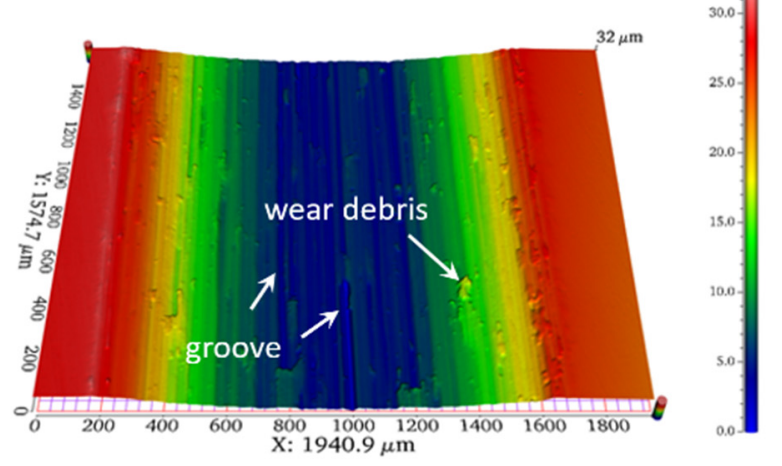

Figure 9. Topology profiles of the samples after wear test: (a) as-received sample; (b) the sample aged at $850{ }^{\circ} \mathrm{C}$ for $4 \mathrm{~h}$; (c) the sample aged at $850{ }^{\circ} \mathrm{C}$ for $15 \mathrm{~h}$. 


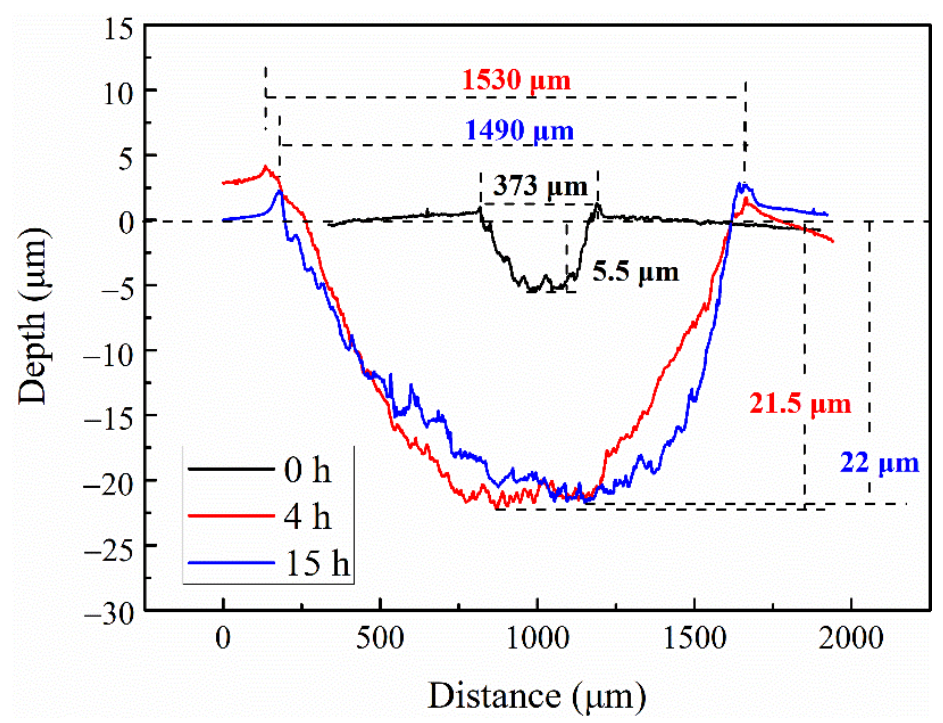

Figure 10. Comparisons of the wear track cross-sectional dimension of $\mathrm{C} 276$ superalloy after aging treatment at $850^{\circ} \mathrm{C}$ with different aging time.

Based on the above analysis, it is found that the precipitation, corrosion resistance, microhardness, friction coefficient, and wear resistance of $\mathrm{C} 276$ superalloy can be greatly affected by aging treatment. Particularly, both the corrosion resistance and wear resistance deteriorated obviously for the C276 superalloy after aging longer than $4 \mathrm{~h}$. Since this superalloy is mainly used in nuclear industry which faces cyclic load and erosion of coolant, long service life is important. Therefore, to avoid the failure of C276 superalloy components, a solution treatment is desired when the processing is conducted at high temperatures for a long time.

\section{Conclusions}

1. The equilibrium phase diagram for a Ni-Cr-Mo-based C276 superalloy was investigated using thermodynamic software Thermal-Calc. Coupled analysis with the precipitate observation, the $\mathrm{M}_{6} \mathrm{C}$ carbides (which are rich in Mo and $\mathrm{Cr}$ ) were found to precipitate at grain boundaries after aging treatment at $800-850{ }^{\circ} \mathrm{C}$ for higher than 4 h. $\mu$ phase and P phase had not been detected.

2. DL-EPR tests were used to estimate the IGC resistance of the aging-treated C276 superalloy. It is found that the degree of sensitization increased with the aging treatment time. It is supposed that the precipitation causes the formation of a $\mathrm{Cr}, \mathrm{W}$ depleted zone adjacent to grain boundaries, deteriorating the corrosion resistance.

3. The microhardness of C276 superalloy increases after aging treatment, which was mainly attributed to the formation of hard $\mathrm{M}_{6} \mathrm{C}$ precipitates. With further increasing the aging treatment time, a slight decrease in the microhardness was observed.

4. For the first time, sliding wear results indicated that both the friction coefficient and wear track dimension increased when C276 superalloy was aging treated. The hard precipitates fell off and acted as the third body during wear process, leading to a great reduction in the abrasion wear resistance.

Author Contributions: Conceptualization, C.Z. and Z.H.; methodology and experiments, P.Z. and X.Z.; writing—original draft preparation, P.Z. and X.Z.; writing—review and editing, C.Z. and Z.H. All authors have read and agreed to the published version of the manuscript.

Funding: This research was funded by the National Key Research and Development Program of China (No. 2019YFA0705300), the Joint Research Fund of Natural Science Foundation of Liaoning-the State Key Laboratory of Rolling and Automation, Northeastern University (2019KF0506) and the Fundamental Research Funds for the Central Universities of China (DUT19JC26). 
Data Availability Statement: Not available.

Conflicts of Interest: The authors declare no conflict of interest.

\section{References}

1. Li, Z.; Han, J.S.; Lu, J.J.; Chen, J.M. Cavitation erosion behavior of Hastelloy C-276 nickel-based alloy. J. Alloys Compd. 2015, 619, 754-759. [CrossRef]

2. Zhu, Y.; Hou, J.; Yu, G.; Qiu, J.; Chen, S.; Zhou, X. Effects of exposing temperature on corrosion performance of weld joint of a Ni-Mo-Cr alloy. J. Fluor. Chem. 2016, 182, 69-75. [CrossRef]

3. Liu, M.; Zheng, J.; Lu, Y.; Li, Z.; Zou, Y.; Yu, X.; Zhou, X. Investigation on corrosion behavior of Ni-based alloys in molten fluoride salt using synchrotron radiation techniques. J. Nucl. Mater. 2013, 440, 124-128. [CrossRef]

4. Wanderka, N.; Bakai, A.; Abromeit, C.; Isheim, D.; Seidman, D.N. Effects of $10 \mathrm{MeV}$ electron irradiation at high temperature of a Ni-Mo-based Hastelloy. Ultramicroscopy 2007, 107, 786-790. [CrossRef] [PubMed]

5. Raghavan, M.; Berkowitz, B.J.; Scanlon, J.C. Electron microscopic analysis of heterogeneous precipitates in Hastelloy C-276. Metall. Trans. A 1982, 13 A, 979-984. [CrossRef]

6. Ahmad, M.; Akhter, J.I.; Akhtar, M.; Iqbal, M.; Ahmed, E.; Choudhry, M.A. Microstructure and hardness studies of the electron beam welded zone of Hastelloy C-276. J. Alloys Compd. 2005, 390, 88-93. [CrossRef]

7. Ernesto, V.A.R.T.; Guastaldi, A.C. Investigation of the metal/porcelain interface in LASER-welded Ni-Cr-Mo alloy. Weld. Int. 2009, 23, 193-199. [CrossRef]

8. Guo, Y.Q.; Wu, D.J.; Ma, G.Y.; Guo, D.M. Trailing heat sink effects on residual stress and distortion of pulsed laser welded Hastelloy C-276 thin sheets. J. Mater. Process. Technol. 2014, 214, 2891-2899. [CrossRef]

9. Zhang, C.; Zhang, L.; Shen, W.; Liu, C.; Xia, Y. The Kinetics of Metadynamic Recrystallization in a Ni-Cr-Mo-Based Superalloy Hastelloy C-276. J. Mater. Eng. Perform. 2016, 25, 545-552. [CrossRef]

10. Zhang, C.; Zhang, L.W.; Shen, W.F.; Li, M.F.; Gu, S.D. Characterization of Hot Deformation Behavior of Hastelloy C-276 Using Constitutive Equation and Processing Map. J. Mater. Eng. Perform. 2014, 24, 149-157. [CrossRef]

11. Zhu, Z.; Zhang, L.; Gu, S. Modeling effects of process parameters on vacuum hot bulge forming of rotor cans. Rare Metal Mater. Eng. 2014, 43, 2257-2261.

12. Zhu, Z.; Zhang, L.; Gu, S. FEM analysis of vacuum hot bulge forming of Hastelloy C-276 thin-walled cylindrical workpiece. J. Cent. South Univ. 2014, 21, 3019-3023. [CrossRef]

13. Zhan, L.; Lin, J.; Dean, T.A. A review of the development of creep age forming: Experimentation, modelling and applications. Int. J. Mach. Tools Manuf. 2011, 51, 1-17. [CrossRef]

14. Unocic, K.A.; Shin, D.; Sang, X.; Cakmak, E.; Tortorelli, P.F. Single-step aging treatment for a precipitation-strengthened Ni-based alloy and its influence on high-temperature mechanical behavior. Scr. Mater. 2019, 162, 416-420. [CrossRef]

15. Ni, M.; Liu, S.; Chen, C.; Li, R.; Zhang, X.; Zhou, K. Effect of heat treatment on the microstructural evolution of a precipitationhardened superalloy produced by selective laser melting. Mater. Sci. Eng. A 2019, 748, 275-285. [CrossRef]

16. Liu, J.; Zhang, J.; Lu, Y.; Li, X.; Li, Z.; Zhou, X. Effect of long-term aging on microstructure and mechanical properties of alloy C276. Acta Metall. Sin. 2013, 49, 763-768. [CrossRef]

17. Akhter, J.I.; Shaikh, M.A.; Ahmad, M.; Iqbal, M.; Shoaib, K.A.; Ahmad, W. Effect of aging on the hardness and impact properties of Hastelloy C-276. J. Mater. Sci. Lett. 2001, 20, 333-335. [CrossRef]

18. Yang, J.; He, Y.; Qin, C.; Zhao, W.; Chen, S.; Gao, Z. Microstructure evolution in a Ni-Mo-Cr superalloy subjected to simulated heat-affected zone thermal cycle with high peak temperature. Mater. Des. 2015, 86, 230-236. [CrossRef]

19. He, Y.M.; Yang, J.G.; Chen, S.J.; Li, Z.; Gao, Z.L. Effect of high-temperature aging on microstructure and mechanical properties of Ni-Mo-Cr based superalloy subjected to simulated heat-affected zone thermal cycle. J. Alloys Compd. 2016, 660, 266-275. [CrossRef]

20. Zhang, C.; Zhang, L.; Cui, Y.; Feng, Q.; Cheng, C. Effects of High-Temperature Aging on Precipitation and Corrosion Behavior of a Ni-Cr-Mo-Based Hastelloy C276 Superalloy. J. Mater. Eng. Perform. 2020, 29, 2026-2034. [CrossRef]

21. Chen, J.; Wang, J.; Yan, F.; Zhang, Q.; Li, Q.A. Corrosion wear synergistic behavior of Hastelloy C276 alloy in artificial seawater. Trans. Nonferrous Met. Soc. China 2015, 25, 661-668. [CrossRef]

22. Chen, J.; Wang, J.; Yan, F.; Zhang, Q.; Li, Q.A. Assessing the corrosion-wear behaviours of Hastelloy C276 alloy in seawater. Lubr. Sci. 2016, 28, 67-80. [CrossRef]

23. Wang, J.; Chen, J.; Chen, B.; Yan, F.; Xue, Q. Wear behaviors and wear mechanisms of several alloys under simulated deep-sea environment covering seawater hydrostatic pressure. Tribol. Int. 2012, 56, 38-46. [CrossRef]

24. Hashim, M.; Duraiselvam, M. Enhancing Tribological and Corrosion Resistance of Hastelloy C-276 through Laser Surface Treatment. Mater. Sci. Forum 2015, 830-831, 659-662.

25. Yilbas, B.S.; Ali, H. Laser texturing of Hastelloy C276 alloy surface for improved hydrophobicity and friction coefficient. Opt. Lasers Eng. 2016, 78, 140-147. [CrossRef]

26. Li, K.M.; Song, K.J.; Guan, J.; Yang, F.; Liu, J. Tribocorrosion behavior of a Ti6Al4V alloy electromagnetic induction nitride layer in a fluorine-containing solution. Surf. Coat. Technol. 2020, 386, 125506.

27. Deng, G.; Zhao, X.; Su, L.; Wei, P.; Zhang, L.; Zhan, L.; Chong, Y.; Zhu, H.; Tsuji, N. Effect of high pressure torsion process on the microhardness, microstructure and tribological property of Ti6Al4V alloy. J. Mater. Sci. Technol. 2021, 94, 183-195. 
28. Sun, W.; Qin, X.; Guo, J.; Lou, L.; Zhou, L. Microstructure stability and mechanical properties of a new low cost hot-corrosion resistant $\mathrm{Ni}-\mathrm{Fe}-\mathrm{Cr}$ based superalloy during long-term thermal exposure. Mater. Des. 2015, 69, 70-80.

29. Jiao, S.; Zhu, G.; Dong, J.; Zhang, Q. Carbide evolution and Mo depletion law in Hastelloy C-276. J. Mater. Eng. 2011, 1, 47-52.

30. Krupp, U. Improving the resistance to intergranular cracking and corrosion at elevated temperatures by grain-boundaryengineering-type processing. J. Mater. Sci. 2008, 43, 3908-3916.

31. Lee, H.T.; Wu, J.L. Intergranular corrosion resistance of nickel-based alloy 690 weldments. Corros. Sci. 2010, 52, 1545-1550. [CrossRef]

32. Liu, X.Y.; Li, M.J.; Gao, F.; Liang, S.X.; Zhang, X.L.; Cui, H.X. Effects of aging treatment on the intergranular corrosion behavior of Al-Cu-Mg-Ag alloy. J. Alloys Compd. 2015, 639, 263-267. [CrossRef]

33. Stratulat, A.; Duff, J.A.; Marrow, T.J. Grain boundary structure and intergranular stress corrosion crack initiation in high temperature water of a thermally sensitised austenitic stainless steel, observed in situ. Corros. Sci. 2014, 85, 428-435. [CrossRef]

34. Luo, G.; Xiao, H.; Li, S.; Wang, C.; Zhu, Q.; Song, L. Quasi-continuous-wave laser surface melting of aluminium alloy: Precipitate morphology, solute segregation and corrosion resistance. Corros. Sci. 2019, 152, 109-119. [CrossRef]

35. Mulligan, C.P.; Wei, R.; Yang, G.; Zheng, P.; Deng, R.; Gall, D. Microstructure and age hardening of C276 alloy coatings. Surf. Coat. Technol. 2015, 270, 299-304. [CrossRef]

36. Deng, G.; Tieu, A.K.; Su, L.; Wang, P.; Wang, L.; Lan, X.; Cui, S.; Zhu, H. Investigation into reciprocating dry sliding friction and wear properties of bulk CoCrFeNiMo high entropy alloys fabricated by spark plasma sintering and subsequent cold rolling processes: Role of Mo element concentration. Wear 2020, 460-461, 203440. [CrossRef]

37. Deng, G.; Tieu, A.K.; Lan, X.; Su, L.; Wang, L.; Zhu, Q.; Zhu, H. Effects of normal load and velocity on the dry sliding tribological behaviour of CoCrFeNiMo0.2 high entropy alloy. Tribol. Int. 2020, 144, 106116. [CrossRef]

38. Wang, L.; Tieu, A.K.; Cui, S.; Deng, G.; Wang, P.; Zhu, H.; Yang, J. Lubrication mechanism of sodium metasilicate at elevated temperatures through tribo-interface observation. Tribol. Int. 2020, 142, 105972. [CrossRef]

39. Zhou, Z.; Shan, Q.; Jiang, Y.; Li, Z.; Zhang, Z. Effect of nanoscale $\mathrm{V}_{2} \mathrm{C}$ precipitates on the three-body abrasive wear behavior of high-Mn austenitic steel. Wear 2019, 436-437, 203009. [CrossRef]

40. Yang, K.; Yu, S.; Li, Y.; Li, C. Effect of carbonitride precipitates on the abrasive wear behaviour of hardfacing alloy. Appl. Surf. Sci. 2008, 254, 5023-5027. [CrossRef] 